\title{
Glossopalatine ankylosis
}

INSERM

\section{Source}

INSERM. (1999). Orphanet: an online rare disease and orphan drug data base.

Glossopalatine ankylosis. ORPHA:141163

Glossopalatine ankylosis is a disorder belonging to the group of oromandibular-limb hypogenesis syndromes (OLHS) and is characterised by the presence of an intraoral band of variable thickness attaching the tongue to the hard palate or maxillary alveolar ridge. 